\title{
The emerging roles of E3 ubiquitin ligases in ovarian cancer chemoresistance
}

\author{
Yang Meng", Lei Qiu\#, Su Zhang, Junhong Han \\ Research Laboratory of Cancer Epigenetics and Genomics, Department of General Surgery, Frontiers Science Center for \\ Disease-related Molecular Network, Cancer Center and National Clinical Research Center for Geriatrics, West China Hospital, \\ Sichuan University, Chengdu 610041, China. \\ \#Yang Meng and Lei Qiu equally contributed to this manuscript.
}

Correspondence to: Prof. Junhong Han, Research Laboratory of Cancer Epigenetics and Genomics, Department of General Surgery, Frontiers Science Center for Disease-related Molecular Network, Cancer Center and National Clinical Research Center for Geriatrics, West China Hospital, Sichuan University, Chengdu 610041, Sichuan, China. E-mail: hjunhong@scu.edu.cn

How to cite this article: Meng Y, Qiu L, Zhang S, Han JH. The emerging roles of E3 ubiquitin ligases in ovarian cancer chemoresistance. Cancer Drug Resist 2021;4:365-81. http://dx.doi.org/10.20517/cdr.2020.115

Received: 12 Dec 2020 First Decision: 4 Jan 2021 Revised: 13 Jan 2021 Accepted: 18 Jan 2021 Available online: 19 Jun 2021

Academic Editor: Godefridus J. Peters Copy Editor: Yue-Yue Zhang Production Editor: Xi-Jun Chen

\begin{abstract}
Epithelial cancer of the ovary exhibits the highest mortality rate of all gynecological malignancies in women today, since the disease is often diagnosed in advanced stages. While the treatment of cancer with specific chemical agents or drugs is the favored treatment regimen, chemotherapy resistance greatly impedes successful ovarian cancer chemotherapy. Thus, chemoresistance becomes one of the most critical clinical issues confronted when treating patients with ovarian cancer. Convincing evidence hints that dysregulation of E3 ubiquitin ligases is a key factor in the development and maintenance of ovarian cancer chemoresistance. This review outlines recent advancement in our understanding of the emerging roles of E3 ubiquitin ligases in ovarian cancer chemoresistance. We also highlight currently available inhibitors targeting E3 ligase activities and discuss their potential for clinical applications in treating chemoresistant ovarian cancer patients.
\end{abstract}

Keywords: Ovarian cancer, chemoresistance, E3 ubiquitin ligases, inhibitor

\section{INTRODUCTION}

\section{Ubiquitination in cancer}

Ubiquitin is evolutionarily conserved and modifies proteins post-translationally for degradation or nondegradative signaling. It is evolutionarily conserved and is covalently coupled to lysine residues sequentially

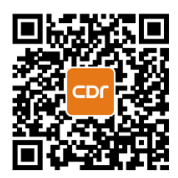




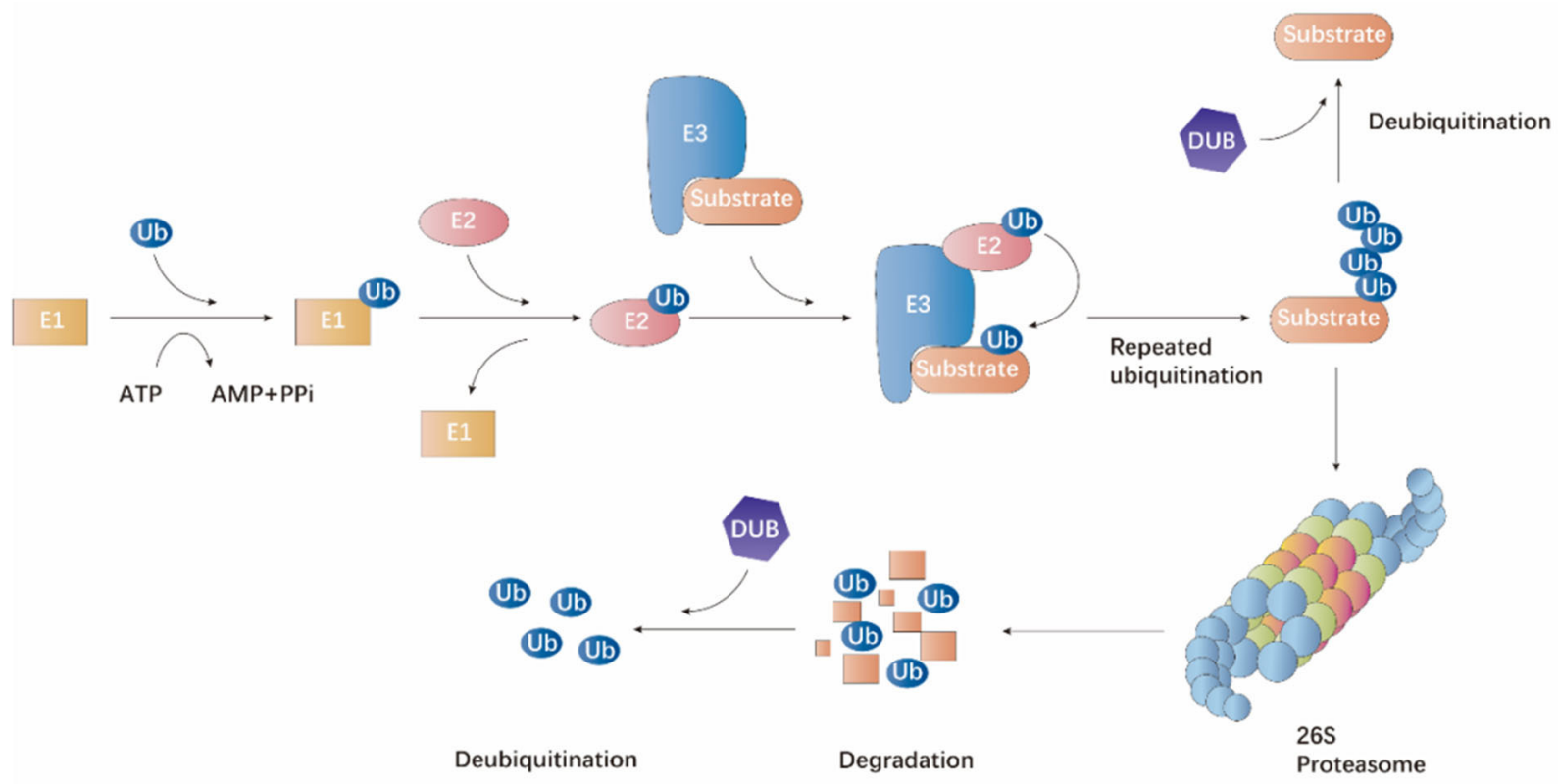

Figure 1. The ubiquitin-proteasome proteolytic pathway. The process of protein degradation via the ubiquitin-proteasome pathway is mediated by an organized milieu of activating (E1), conjugating (E2) and ligating (E3) enzymes to regulate the ligation of ubiquitin to the protein substrate. The substrate attached with multiple ubiquitin molecules are targeted to the $26 \mathrm{~S}$ proteasome complex for degradation. Ubiquitin molecules can be removed by the action of deubiquitinating enzymes.

by activating (E1), conjugating (E2) and ligating (E3) enzymes ${ }^{[1,2]}$. The C-terminus of ubiquitin is activated by an E1 activating enzyme first and then transferred to the active site of an E2 conjugating enzyme [Figure 1]. Subsequently, an E3 ubiquitin ligase bridges the target protein and the E2-ubiquitin intermediate to catalyze isopeptide bond formation between the substrate lysine and the ubiquitin C-terminal glycine [Figure 1] ${ }^{[3]}$. The cellular functions of ubiquitination involve several complicated cellular processes, including proteasomal degradation of proteins, endocytosis, protein-protein interactions, intracellular trafficking, cell cycle progression, DNA repair, autophagy, inflammatory signaling, and modulation of enzymatic activity ${ }^{[4]}$. The deubiquitination process is also a crucial step mediated by ubiquitin recycling enzymes in proteasomal pathway, which is important for maintaining cellular ubiquitin homeostasis. Deubiquitinating enzymes (DUBs) cleave ubiquitin residues from protein substrates conjugated with ubiquitin and the covalent links between ubiquitin-ubiquitin [Figure 1$]^{[5]}$. Similar with ubiquitin ligases, DUBs are also implicated in the adjustment of various cellular activities, including DNA repair, cell cycle progression, chromosome segregation, gene expression, and spermatogenesis ${ }^{[5-7]}$. Therefore, dysregulation of ubiquitination may lead to human organism disorders such as cancer.

The approval and effective clinical application of proteasomal inhibitors for the treatment of multiple myeloma ${ }^{[8,9]}$ has inspired researchers to use various aspects of the ubiquitination system as targets for treatment of malignant cancers as well as other diseases ${ }^{[1]}$. Advancement in technologies such as proteomic mass spectrometry and development of ubiquitin/ubiquitination-specific antibodies, have provided possibilities to trace ubiquitination precisely in a genome-wide manner ${ }^{[1]}$. Consequently, numerous studies have uncovered correlations between dysregulation of the ubiquitination-proteasome system and cancer. For example, some $\mathrm{Cbl}$ family ubiquitin ligases promote cancer by mediating lysosomal sorting and degradation of RTKs ${ }^{[10]}$. The E3 ligase c-Cbl is frequently dysregulated in myelodysplasticmyeloproliferative neoplasms and is also couped with myelodysplastic syndromes, myeloid neoplasms, and primary colorectal cancer ${ }^{[1]}$. Therefore, ubiquitination plays an important role in cancer. 


\section{Ovarian cancer chemoresistance}

GLOBOCAN estimated in 2018 that there would be nearly 300,000 newly diagnosed cases of ovarian cancer per year and around 185,000 would die from this cancer ${ }^{[11]}$. Ovarian cancer is the most deadly gynecological cancer. Because of lacking noticeable early symptoms, approximately $70 \%$ of the ovarian cancer patients are diagnosed in advanced stages and about $85 \%$ of the patients have cancer that already metastasized to other organs ${ }^{[12,13]}$. Apart from development of novel targeted therapies, such as PARP (poly ADP-ribose polymerase) inhibitors, and application of intraperitoneal delivery, the five-year survival rate of ovarian cancer patients with advanced cancer remains only $20 \%-40 \%{ }^{[14]}$. At present, the standard therapeutic regimen for ovarian cancer patients is tumor debulking surgery followed by chemotherapy treatment with platinum derivative (cisplatin or carboplatin) combined with paclitaxel. This therapy manifests encouraging effects in many terminal stage epithelial ovarian cancer patients. However, the development of chemoresistance is a chief barrier against the improvement of ovarian cancer patient outcome ${ }^{[15]}$. Therefore, understanding the mechanisms of chemoresistance development is crucial for overcoming ovarian cancer treatment failure.

The mechanisms of ovarian cancer chemoresistance are remarkably elusive. Studies have uncovered that chemoresistance developed through several traditional mechanisms, including diminished drug uptake, increased drug efflux from cells ${ }^{[16,17]}$, modified drug target, upregulation of DNA repair systems, and enhanced replicative bypass of platinum-DNA adducts ${ }^{[18]}$, as well as diminished ratio of drug-induced DNA damage in the resistant cells ${ }^{[19]}$. In recent years, E3 ubiquitin ligases have been manifested to play key roles in chemoresistance through degradation of various chemoresistance-related substrates in ovarian cancer.

In this manuscript, we review the emerging roles of E3 ubiquitin ligases in ovarian cancer chemoresistance. We also summarize inhibitors that target E3 ubiquitin ligases which may help overcome chemoresistance and improve patient outcome. Finally, we highlight challenges and restrictions in targeting E3 ubiquitin ligases as ovarian cancer chemotherapy.

\section{CLASSIFICATION OF E3 UBIQUITIN LIGASES}

Human E3 ubiquitin ligases comprise more than 600 members and are identified in mammalian ubiquitination cascades ${ }^{[20-22]}$. E3 ubiquitin ligases are classified into three families based on differences in structure and function, mainly comprising the HECT (homologous to the E6-associated protein carboxyl terminus) domain family, the RING (really interesting new gene) finger family, and the RING in-betweenRING (RBR) E3 ubiquitin ligases ${ }^{[23,24]}$.

There are roughly 30 HECT domain-containing E3 ligases in mammals. Among their many functions, HECT domain E3s determine ubiquitination specificity and play prominent roles in the trafficking of many receptors, regulating the immune response and several signaling pathways in cell proliferation ${ }^{[25]}$.

As the largest family of E3 ubiquitin ligases, substrate of RING-finger E3 ubiquitin ligases involve various cellular processes, including cell metabolism, cell proliferation, apoptosis, differentiation and DNA repair. RING-finger E3 ligases differ from the HECT domain E3s in that they do not form catalytic intermediates with ubiquitin. In contrast, the RING-finger domain serves as a platform that bridges the E2 conjugating enzyme and the substrate. Evidence shows that RING-finger domains can also activate E2 ubiquitinconjugating enzymes allosterically ${ }^{[26]}$.

The RBR E3 ligases, a family of RING-HECT hybrids, contain an RBR module (RING1-IBR-RING2) comprising two RING domains (RING1 and RING2) connected via an in-between-RING (IBR) domain ${ }^{[27,28]}$. RBR E3 ubiquitin ligases differ from their RING-type E3 cousins mainly because they possess an active site, a feature not observed in other RING-type E3s ${ }^{[29]}$. Similar to canonical RING-type E3s, the 
RING1 domain of the RBR module binds ubiquitin-loaded E2 enzymes (E2-Ubs), whereas an essential active-site Cys in RING2 recruits ubiquitin from an E2-Ub to generate a covalent E3-Ub intermediate, which is otherwise only seen in HECT-type E3s ${ }^{[29]}$. RBR E3s are therefore regarded as RING-HECT hybrids. HHARI and Parkin were the first two RBR members revealed to have the hybrid mechanism ${ }^{[29]}$. TRIAD1, RNF144A, HOIP, and HOIL-1L have later been verified with this active-site Cys for catalytic $\operatorname{activity}^{[30-33]}$.

E3 ubiquitin ligases play crucial roles in the ubiquitin-proteasome pathway, thus may be critical to cancer progression and chemoresistance. Indeed, multiple studies have indicated prominent roles of E3 ubiquitin ligases in ovarian cancer chemoresistance.

\section{E3 UBIQUITIN LIGASES IN OVARIAN CANCER CHEMORESISTANCE}

\section{The HECT domain E3 ligases in ovarian cancer chemoresistance}

The HECT family consists only 28 of the 600 members of human E3 ligases ${ }^{[34]}$. Based on the protein-protein interaction domains that determine their substrate specificity, the HECT-type E3s can be further classified into three subfamilies: C2-WW-HECT E3s possessing WW (tryptophan-tryptophan) domains, HERC E3s containing RLDs (RCC1-like domains), and SI(ngle)-HECT E3s lacking either WW or RLDs domains $\left[\right.$ Figure 2] ${ }^{[2,35]}$. Currently, the most well studied HECT domain E3 ligases that relate to chemoresistance are ubiquitin protein ligase E3 component n-recognin 5 (UBR5/EDD ), HECT, UBA, and WWE domain containing 1 (HUWE1/MULE) and HECT-Type E3 Ubiquitin Transferase Itchy Homolog (ITCH ), among which UBR5/EDD and ITCH have been reported to be implicated in ovarian cancer chemoresistance.

\section{NEDD4 family}

The NEDD4 family of well-characterized HECT domain-containing E3 ubiquitin ligase are highly evolutionarily conserved from yeast to humans ${ }^{[36]}$. As shown in Figure 2, the NEDD4 family contains nine mammalian members in humans, including NEDD4 (NEDD4-1), NEDD4-2 (NEDD4L), WW domaincontaining E3 ubiquitin protein ligase 1, WWP2/atropine-1-interacting protein 2 (AIP2), SMAD-specific E3 ubiquitin protein ligase 1 (SMURF1), SMURF2, ITCH/atropine-1 interaction protein 4 (AIP4), NEDL1 (HECW1), and NEDL2 (HECW2 $)^{[37]}$. The structure of NEDD4 family E3 ligase consists of a catalytic C-terminal HECT domain for Ub protein ligation, 2-4 WW domains and an N-terminal C2 domain as $\mathrm{a} \mathrm{Ca}^{2+}$ or phospholipid-binding motif for the cell membrane substrate binding ${ }^{[38,39]}$. Recent studies have identified that NEDD4 family enzymes have been demonstrated to play a key role in the progression of various cancers and drug resistance in cancer therapy. One study showed significantly reduced NEDD4-2 protein expression in invasive ovarian epithelial cancer tissues compared to ovarian noncancer tissue ${ }^{[40]}$. In addition, NEDD4 is highly expressed in erlotinib-resistant NSCLC cells and cisplatinresistant nasopharyngeal carcinoma cells ${ }^{[4]}$. Nonetheless, upregulation of NEDD4 resensitized multiple myeloma cells to bortezomib treatment via ubiquitination of Akt and degradation of pAkt-Ser473, while downregulation of NEDD4 resulted in bortezomib resistance in multiple myeloma cells ${ }^{[42]}$. What's more, Akkaya et al ${ }^{[43]}$ also demonstrated NEDD4 as a ubiquitin ligase for ATP binding cassette subfamily B member 1, which is a multidrug resistance pump that mediates drug resistance, indicating that NEDD4 directly participates in drug resistance. These pieces of evidence suggest an important role of NEDD4 in the regulation of chemoresistant ovarian cancer.

\section{ITCH}

ITCH is classified as a NEDD4 family E3 ligase with a C-terminal HECT domain for E3 ligase activity and WW domains for substrate recruiting ${ }^{[44]}$. However, the intramolecular interaction of ITCH catalytic HECT domain with its WW domains blocks its ubiquitination activity ${ }^{[45]}$.ITCH regulates the transcriptional activity of several transcription factors including NF-kB1 and JUNB, probably playing an important role in inflammatory signaling pathways. ITCH forms a complex with FLIP (FLICE-like inhibitory protein) and 


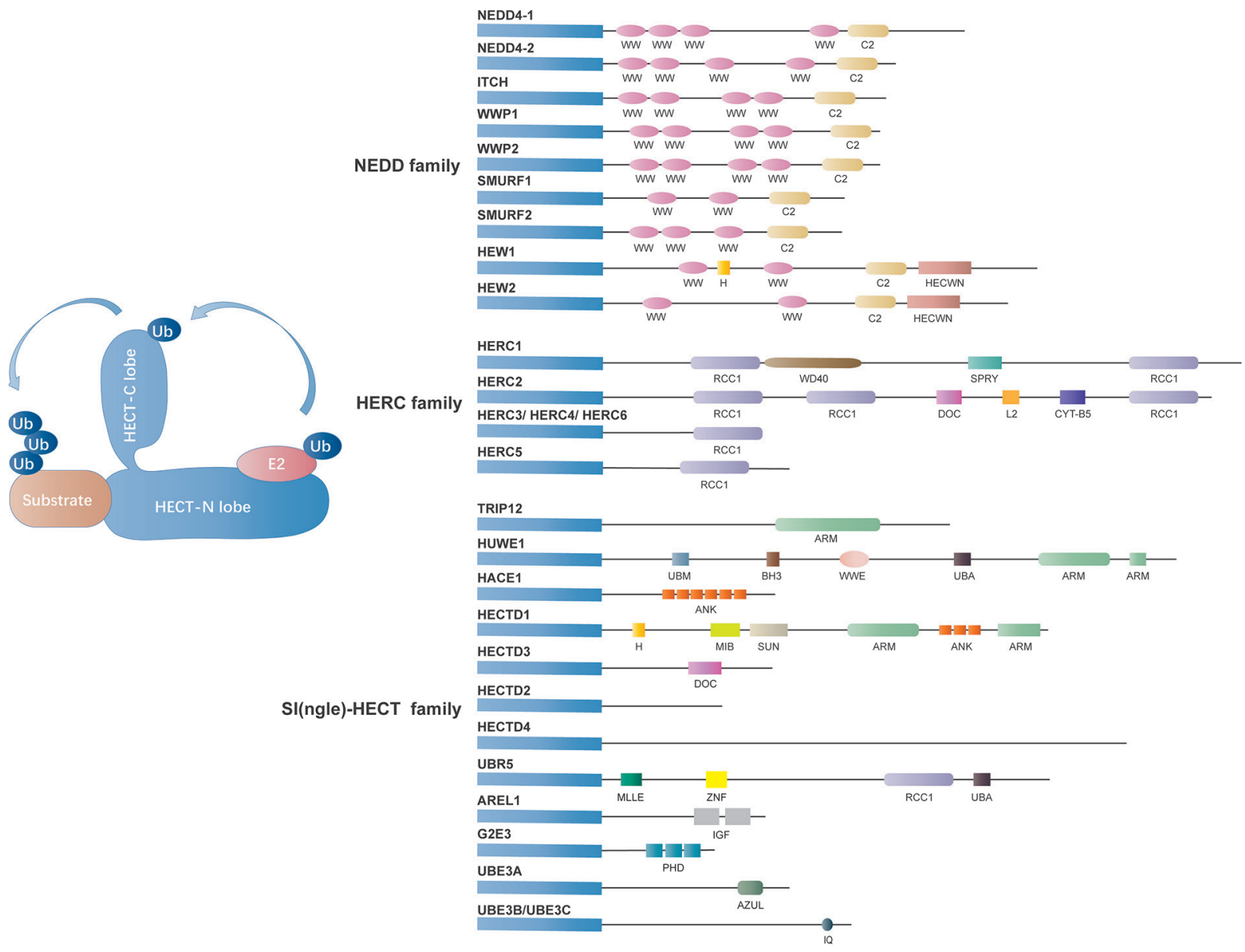

Figure 2. Classification of the HECT domain E3 ligases. The mammalian HECT E3 ligases have been classified into three subgroups, including HERC family (HERC E3s containing RLDs family, 6 members), NEDD4 family (C2-WW-HECT E3s possessing WW domains family, 9 members) and SI(ngle)-HECT family [SI(ngle)-HECT E3s lacking either WW or RLDs domains family, 13 members] [Figure 1]. The HECT domain is comprised of a smaller C-terminal lobe consisting of the active-site cysteine residue and a larger $\mathrm{N}$-terminal lobe including the E2-binding site. The conjugation between ubiquitin with a protein substrate consists of three steps: activated ubiquitin binding to a specific cysteine residue of one of several E2s, loading ubiquitin on themselves through the formation of a ubiquitinthioester intermediate with the catalytic cysteine located at the $C$ terminus of the HECT domain, and immediately deliver of ubiquitin to the protein substrates.

mediates its degradation and tumor necrosis factor $\alpha$-induced apoptosis ${ }^{[46,47]}$. Cisplatin treatment induces ITCH-FLIP-p53 interaction, colocalization and FLIP degradation in chemosensitive but not chemoresistant ovarian cancer cells ${ }^{[48]}$. p53-FLIP interaction and FLIP ubiquitination can also be facilitated by inhibiting Akt function ${ }^{[48]}$. Abedini et al. ${ }^{[48]}$ further demonstrated that gelsolin was highly expressed in chemoresistant ovarian cancer cells and cisplatin failed to abolish the intact gelsolin-FLIP-ITCH interaction, leading to the dysregulation of the downstream responses.

\section{UBR5/EDD}

The ubiquitin protein ligase E3 component N-recognin 5 (UBR5, also known as EDD) belongs to the SI(ngle)-HECT family of E3 ubiquitin ligases that are involved in DNA damage response by suppressing RNF168, an E3 ligase that mediates the accumulation of ubiquitynated-H2A and $-\mathrm{H} 2 \mathrm{AX}$ at DNA damage sites, and G2 checkpoint control ${ }^{[49-52]}$. UBR5 amplification in mRNA levels has been demonstrated in ovarian and breast cancer ${ }^{[53]}$. UBR5 is considered as an undesirable prognostic factor for patients with serous epithelial ovarian cancer due to its modulation in cisplatin resistance ${ }^{[54]}$. Bradley et al. ${ }^{[55]}$ also reported that UBR5 enhanced cell survival and cisplatin resistance and might serve as a therapeutic target for epithelial ovarian cancer. They further showed that UBR5 might have modulated ovarian cancer cell 
survival through regulating expression of the prosurvival protein myeloid cell leukemia sequence $1(\mathrm{Mcl}-1)^{[55]}$. As a novel ubiquitin ligase for the proapoptotic protein modulator of apoptosis protein 1 (MOAP-1, also known as MAP-1), UBR5 influences ovarian cancer cell cisplatin resistance by mediating MOAP-1 ubiquitination and degradation through cooperation with Dyrk2 kinase ${ }^{[56,57]}$. UBR5 upregulation in recurrent and platinum-resistant ovarian cancers indicates that targeting UBR5 may be an effective strategy for chemoresistant ovarian cancer treatment ${ }^{[57]}$.

\section{RING-finger domain E3 ligases in ovarian cancer chemoresistance}

RING-finger domain E3 ubiquitin ligases contain either a domainor subunit with a RING motif. They can be either monomeric or members of multi-subunit E3 ligase complexes ${ }^{[58]}$. Previous evidence indicates that the RING-domain E3 ubiquitin ligases including Cullin-RING E3 ligase complexes such as SCF complex (SKP1, Cullin and F-box protein), the APC/C complex, as well as monomeric XIAP, MDM2, MUL-1, Pirh2, and SIAH2 may all be associated with ovarian cancer chemoresistance.

\section{Cullin-RING E3 ubiquitin ligases}

Cullin-RING E3 ubiquitin ligases are the most extensively studied subfamily of multi-subunit complex RING ligases [Figure 3]. Cullin-RING ligase complexes are generally comprised of four indispensable subunits that include a Cullin scaffold (Cullin 1, Cullin 2, Cullin 3, Cullin 4A, Cullin 4B, Cullin 5, Cullin 7, or Cullin 9), a RING-finger protein (RBX1 or RBX2), an adaptor protein (SKP1, Elongin B, Elongin C, or DDB1), and a substrate recognition protein (over 400 known substrates) ${ }^{[59-62]}$. As the central coordinator in forming the Cullin-RING E3 complex, the Cullin scaffold provides a platform bridging the RING finger subunit with the adaptor subunit ${ }^{[61]}$. The RING-finger subunit acts as a docking site for the substrate recognition module and E2 to promote transfer of ubiquitin from E2 to the recruited substrate. The substrate recognition module interacts with the adaptor protein and determines substrate specificity ${ }^{[61,63]}$. Cullin-RING E3 ubiquitin ligases are responsible for approximately $20 \%$ of cellular ubiquitination events conducted by ubiquitin-proteasome system ${ }^{[64,65]}$.

The SCF E3 ubiquitin ligase complex is a member of the Cullin-RING family and consists of CUL1, SKP1, and F-box proteins ${ }^{[63]}$. One of the typical F-box proteins $\beta$-TRCP promotes protein degradation by recognizing the phosphorylation of many key signaling molecules and plays a crucial role in cell cycle regulation, DNA damage response, and cancer development ${ }^{[66,67]}$. Extensive studies have demonstrated that AEBP2 (a zinc finger protein) ubiquitination and destruction mediated by SCF- $\beta$-TRCP ubiquitin ligase complex control cisplatin resistance in ovarian cancer ${ }^{[68]}$.

FOXO5 overexpression has been reported in ovarian cancer ${ }^{[69]}$. As a tumor suppressor and a TGF- $\beta$ / SMAD4 target gene, methylation of FBXO32 promoter correlates with poor ovarian cancer prognosis while reintroduction of FBXO32 can sensitize the cells to cisplatin treatment ${ }^{[70]}$. FBXL7 plays a prominent role in ovarian cancer survival and its overexpression in ovarian cancer patients is implicated in paclitaxel resistance and poor prognosis ${ }^{[71,72]}$. Although the exact mechanism regarding how FBXL7 influences ovarian cancer chemoresistance has not yet been well clarified, a study in gastric cancer suggests that FBXL7 adjusts survivin expression through the ubiquitin-proteasome pathway ${ }^{[73]}$. AURKA (auroral kinase A ) down-regulates FBXL7 and subsequently inhibits survivin degradation and increases survivin protein level, leading to enhanced drug resistance ${ }^{[73]}$. FBXL10, also known as Ndy1, JHDM1B or KDM2B, was initially characterized as a $\mathrm{H} 3 \mathrm{~K} 36$ demethylase, which controls cell proliferation and senescence by regulating $\mathrm{p} 15^{[74,75]}$. Yan et al. ${ }^{[76]}$ demonstrated that mirR146b sensitized ovarian cancer cells to paclitaxel and cisplatin and enhanced cell proliferation by inhibiting FBXL10.

Jazaeri et al ${ }^{[13]}$ manifested that CUL3 interacted with KEAP1 (kelch-like erythroid cell associated protein-1) and RBX1 (RING-box 1) to form the CRL3-KEAP1 ubiquitin ligase, while inhibition of CRL3 sensitized both Skov3 and ES2 cells to cisplatin. 

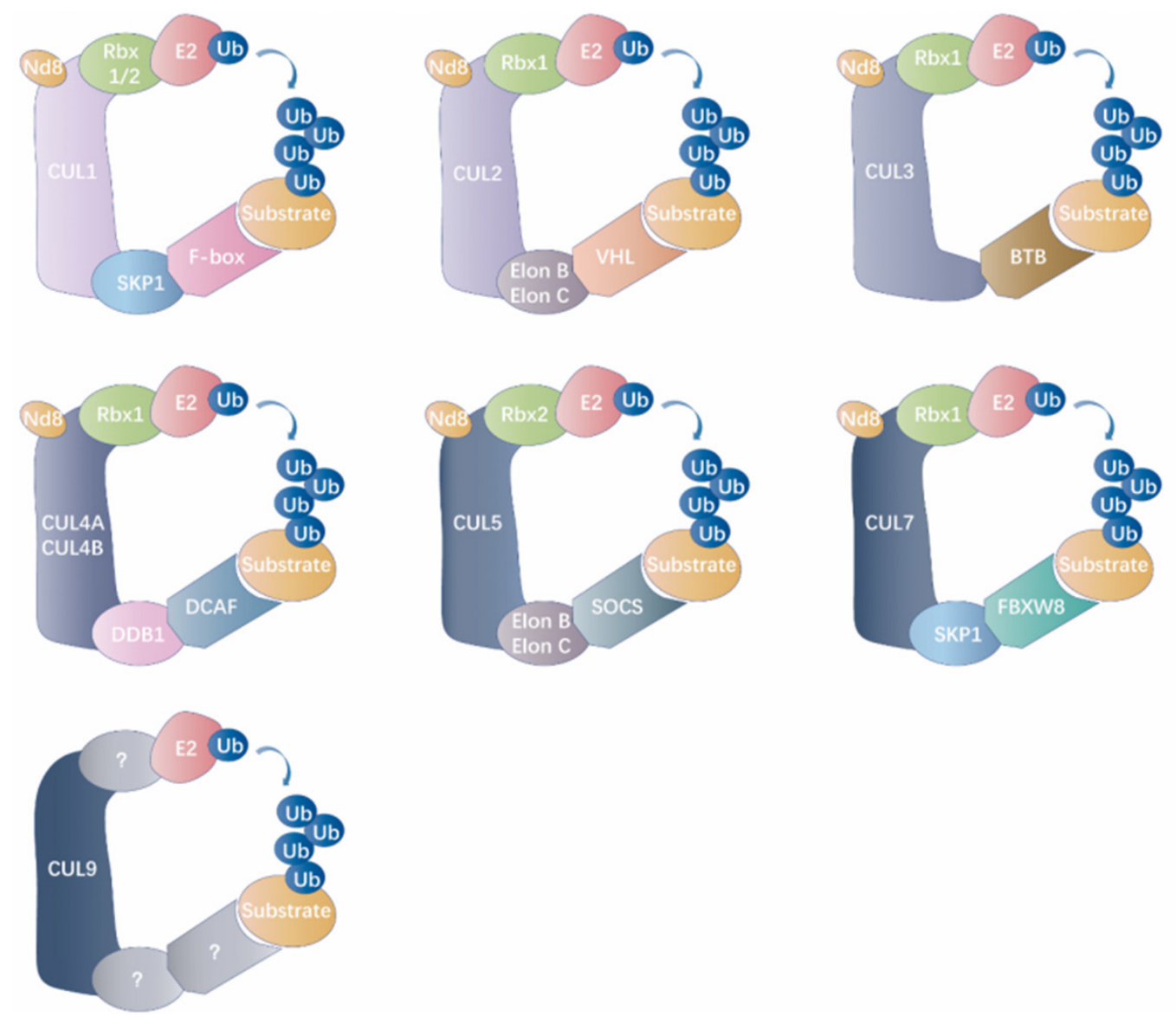

Figure 3. Classification of the cullin-RING E3 ubiquitin ligases. The general catalytic core of cullin-RING ligases (CRLs) is comprised of a RING protein and a cullin-family member, which delimits this modular category of RING ubiquitin ligase. NEDD8 (Nd8, neural precursor cell expressed developmentally down-regulated protein 8), as a ubiquitin-like modifier, efficiently activates Cullins by the covalent conjugation. Each Cullin exploits modular assembly to enroll different substrates to a general catalytic core by altering its substrate receptors. Cullin family members from different organisms recruit RING-finger proteins (Rbx1/2), adaptor proteins (SKP1 for CUL1/7, Elon B/Elon C for CUL2/5, BTB for CUL3, and DDB1 for CUL4A/B) and receptor proteins (F-box proteins for CUL1, VHL for CUL2, DCAF proteins for CUL4A/B, SOCS protein for CUL5, and FBXW8 protein for CUL7) for assembling multi-subunit complexes into ubiquitinated specific substrate proteins. However, the assembly of the CRL9 complex is ambiguous. Nd8: NEDD8; Ub: ubiquitin; CUL: cullin; SKP1: S-phase kinase-associated protein 1; VHL: von Hippel-Linda; BTB: broad complex, tramtrack, 'bric-a-brac'; CRL: cullin RING ligase; DCAF: DDB1 CUL4 associated factor; DDB1: DNA damage-binding protein 1; RING: really interesting new gene; SOCS: suppressors of cytokine signalling.

CRL4 ${ }^{\mathrm{CDT} 2}$ repression and CDT1 accumulation are critical biochemical events contributing to the genotoxic effects of MLN4924 in ovarian cancer cells [Table 1] ${ }^{[62]}$. Moreover, VPRBP is upregulated in high-grade ovarian patient tumors and CRL4 ${ }^{\text {VPRBP-DCAF1 }}$ regulates the degradation and nonproteolytic activation of the cell transcription factor Foxm ${ }^{[77]}$. Our previous study has also illustrated that CRL4 ${ }^{\mathrm{Cu} / / \mathrm{DDB} 1}$ E3 ubiquitin ligase regulates ovarian cancer drug resistance by targeting the anti-apoptotic protein BIRC ${ }^{[78]}$. Jang et al ${ }^{[79]}$ further showed that deficiencies in RepID, CRL4, or RBBP7 delayed mitotic exit, increased genomic instability, and enhanced sensitivity of ovarian cacner cells to paclitaxel.

Given the emerging role of Cullin-RING ubiquitin ligases in ovarian cancer chemoresistance, targeting the activity of Cullin-RING complexes may be an efficacious anticancer strategy for targeted ovarian cancer therapy. 
Table 1. E3 ligase and their impact on cancer drug resistance

\begin{tabular}{|c|c|c|c|c|c|c|c|c|}
\hline Classification & & E3 ligase & & $\begin{array}{l}\text { Targeted } \\
\text { ubstrate }\end{array}$ & Associated pathway & $\begin{array}{c}\text { Drug } \\
\text { resistance }\end{array}$ & Inhibitor & Ref. \\
\hline \multirow{3}{*}{$\begin{array}{l}\text { HECT E3 } \\
\text { ligases }\end{array}$} & & MOAP-1 & Intrinsic apoptosis pathway & Cisplatin & & {$[54,57]$} \\
\hline & \multicolumn{3}{|l|}{$\mathrm{ITCH}$} & FLIP & & Cisplatin & & {$[46,153]$} \\
\hline & \multicolumn{3}{|l|}{ NEDD4 } & $A B C B 1$ & & & & {$[43]$} \\
\hline \multirow{8}{*}{$\begin{array}{l}\text { RING-Domain } \\
\text { E3 ligases }\end{array}$} & \multirow{8}{*}{$\begin{array}{l}\text { Cullin-RING } \\
\text { E3 ligases }\end{array}$} & \multirow{4}{*}{$\begin{array}{l}\text { SCF } \\
\text { ubiquitin } \\
\text { ligase }\end{array}$} & $\beta$-TRCP & \multirow[t]{2}{*}{ AEBP2 } & Cell proliferation & Cisplatin & & [68] \\
\hline & & & FBxo32 & & Cell proliferation & Cisplatin & & {$[70]$} \\
\hline & & & FBXL7 & Survivin* & $\begin{array}{l}\text { Ubiquitin proteasome } \\
\text { pathway }\end{array}$ & $\begin{array}{l}\text { Cisplatin/ } \\
\text { paclitaxel }\end{array}$ & & [71-73] \\
\hline & & & FBXL10 & $\mathrm{P} 15^{\star}$ & Cell proliferation & $\begin{array}{l}\text { Cisplatin/ } \\
\text { paclitaxel }\end{array}$ & & {$[74,75]$} \\
\hline & & CRL3 & KEAP1 & $\mathrm{Nrf2}{ }^{\star}$ & Cell survival & Cisplatin & MLN4924 & [13] \\
\hline & & CRL4 & $\begin{array}{l}\text { CDT2/ } \\
\text { DCAF2 }\end{array}$ & CDT1 & $\begin{array}{l}\text { Cell survival and } \\
\text { proliferation }\end{array}$ & Cisplatin & MLN4924 & {$[62]$} \\
\hline & & & $\begin{array}{l}\text { VPRBP- } \\
\text { DCAF1 }\end{array}$ & Foxm $1^{\star}$ & Cell cycle & & & {$[77]$} \\
\hline & & & & & STAT1-STAT3 pathway & Cisplatin & MLN4924 & {$[78]$} \\
\hline \multirow[t]{6}{*}{$\begin{array}{l}\text { RING-domain } \\
\text { E3 ligase }\end{array}$} & \multicolumn{3}{|l|}{ XIAP } & P53 & $\begin{array}{l}\text { Caspase3 } \\
\text { PI3K-AKT pathway }\end{array}$ & Cisplatin & & {$[85,88]$} \\
\hline & \multicolumn{3}{|l|}{ MDM2 } & P53 & Apoptosis pathway & Cisplatin & Nutlins & [97] \\
\hline & \multicolumn{3}{|l|}{ MUL-1 } & AKT & PI3K-AKT pathway & Cisplatin & & [111] \\
\hline & \multicolumn{3}{|l|}{$\mathrm{APC} / \mathrm{C}$} & PLK1 & Apoptosis pathway, mitotic & $\begin{array}{l}\text { Cisplatin/ } \\
\text { paclitaxel }\end{array}$ & & [81-83] \\
\hline & \multicolumn{3}{|l|}{ Pirh2 } & Twist1 & EMT & Cisplatin & & {$[113,114]$} \\
\hline & \multicolumn{3}{|l|}{ Siah2 } & $\mathrm{HIF}-1 \alpha^{\star}$ & Hypoxia, MAPK signaling & Platinum & Menadione & {$[119,126,127]$} \\
\hline RBR ligase & \multicolumn{3}{|l|}{ RNF31/HOIP } & $\begin{array}{l}\text { Caspase3/ } \\
\text { Caspase }{ }^{\star}\end{array}$ & JNK pathway & Cisplatin & & {$[24,131]$} \\
\hline
\end{tabular}

The substrate proteins with asterisk mark may be involved in the regulation of ovarian cancer cisplatin resistance.

\section{Multi-subunit RING E3 ligase - APC/C}

The APC/C (anaphase-promoting complex/cyclosome) is the major ubiquitin ligase involved in the regulation of mitosis ${ }^{[80,81]}$. Raab et al ${ }^{[82]}$ reported that by eliminating the anti-apoptotic shielding through MCL-1 inhibition and blocking the activity of APC/C, the apoptosis-resistant and slippage prone HGSOCs were sensitized to the frontline therapy including paclitaxel. Belur Nagaraj et al. ${ }^{[83]}$ uncovered that longterm cisplatin treatment induced mitotic exit vulnerability in the presence of APC/C dysfunction along with cisplatin-resistance, where $\mathrm{APC} / \mathrm{C}^{\mathrm{CDC} 20}$ inhibition increased the sensitivity of pharmacologic PLK1 inhibition, which in turn diminished cisplatin-resistant cell survival and aggravated spindle checkpoint response in cisplatin resistant ovarian cancer cells.

\section{XIAP}

As a member of the inhibitor of apoptosis protein family, X-linked inhibitor of apoptosis protein (XIAP) contains three baculoviral inhibitory repeat domains at the $\mathrm{N}$-terminus, which are associated with direct caspase inhibition ${ }^{[84]}$. XIAP also comprises a C-terminal RING-finger domain with E3 ubiquitin ligase activity through the NEDD8 conjugation pathway, targeting effector caspases for neddylation and inactivation ${ }^{[85]}$. XIAP does not only regulate apoptosis, but also influence mitogenic kinase signaling, copper homeostasis, inflammatory signaling and immunity, as well as tumor metastasis. It has previously been reported that cisplatin down-regulates XIAP in chemosensitive ovarian cancer cells, whereas chemoresistant cells are not affected ${ }^{[86]}$. Furthermore, XIAP determines chemoresistance, since its downregulation in chemoresistant cells sensitizes cells to the cytotoxicity induced by cisplatin, whereas its overexpression in chemosensitive cells can lead to chemotherapy tolerant phenotypes ${ }^{[86,87]}$. Inhibition of p53-mediated cell death and upregulation of the PI3K/Akt pathway partially contribute to the antiapoptotic effects of XIAP ${ }^{[88]}$. 
XIAP itself can be ubiquitinated and degraded through the $26 \mathrm{~S}$ proteasome under specific cellular condition. One study suggests that XIAP is a potential substrate of HtrA1 and the HtrA1-mediated XIAP ubiquitination and degradation is sufficient to sensitize cells to chemotherapy, proposing that restoring the expression of HtrA1 would be a prospective treatment strategy against ovarian cancer chemoresistance ${ }^{[89]}$. Cisplatin induces XIAP content decrease and cytosolic HtrA2/Omi level increase in cisplatin-sensitive ovarian cancer cells ${ }^{[90]}$. In addition, HtrA2/Omi level change correlates with the XIAP downregulation, caspase- 3 activation, and apoptotic response, suggesting that cisplatin resistance probably due to XIAP neutralizing caspase-3 activation and lower cytosolic HtrA2/Omi level in response to cisplatin in human ovarian cancer cells ${ }^{[90]}$.

\section{$M D M 2$}

As a RING finger dependent E3 ubiquitin ligase, murine double minute 2 ( MDM2, also known as HDM2) plays crucial roles in regulating 553 protein ubiquitination and degradation ${ }^{[9-96]}$. In addition, it is a component of the Trim28-ERBB4-MDM2 complex linking growth factor and DNA damage repair pathways. Recently, MDM2 inhibitors have been assessed in clinical trials. Mir et al. ${ }^{[97]}$ suggest that MDM2 antagonists induce apoptosis and are able to overcome chemoresistance in TP53 wild-type ovarian cancer cells when synergized with cisplatin. The authors used small molecules called nutlins to inhibit the binding of p53-MDM2 and induce apoptosis in chemoresistant ovarian cancer by activating p53 pathway ${ }^{[97]}$. Meanwhile, Wu et al.$^{[98]}$ demonstrated that F14 overcame cisplatin resistance of HGSOC (high-grade serous ovarian cancer) by accelerating MDM2-regulated p53-R248Q ubiquitination and degradation . More recently, the research of Cui et al. ${ }^{[99]}$ indicated that overexpression of CCDC69 protein activated p14 ${ }^{\mathrm{ARF}}$ MDM2-p53 pathway and increased the cisplatin sensitivity in chemoresistant ovarian cancer. Intriguingly, the expression of CCDC69 protein extended the half-life of $\mathrm{p} 53$ and $\mathrm{p} 14{ }^{\mathrm{ARF}}$ proteins and shortened the halflife of MDM2 $\operatorname{protein}^{[99]}$.

MUL-1

MUL-1 (mitochondrial E3 ubiquitin protein ligase 1, also known as MULAN ${ }^{[34]}$, MAPL $^{[100,101]}$, GIDE ${ }^{[102]}$, and $\mathrm{HADES}^{[103,104]}$ ) exhibits weak E3 ubiquitin-protein ligase activity ${ }^{[105,106]}$, and it is one of the three known mitochondrial E3 ubiquitin ligases involved in mitophagy ${ }^{[107,108]}$, apoptosis ${ }^{[101,102,108]}$, and innate immune response $^{[109,110]}$. Studies uncovered that metformin conducted its antitumor activity by downregulating AKT protein expression via MUL-1 E3 ligase ${ }^{[111]}$. These findings suggest that MUL-1 regulates metforminmediated AKT degradation and the potential of using metformin as a therapeutic strategy in treatment against chemoresistant ovarian cancer cell.

\section{Pirh2}

Pirh2 (p53-induced RING-H2 protein) was initially identified as an ARNIP (androgen receptor N-terminalinteracting protein), which displayed ubiquitin ligase activity toward p53, p73, HDAC1, and $\mathrm{CDKN} 1 \mathrm{~B}^{[112]}$. Pirh2, along with Mdm2, was later found to be one of the major ubiquitin ligases targeting p53, preferentially acts on tetrameric $\mathrm{p} 53$, leading to proteasomal degradation ${ }^{[113,114]}$. Yang-Hartwich et al. ${ }^{[115]}$ showed that p53-Pirh2 complex promoted Twist1 degradation and inhibited EMT (epithelial-mesenchymal transition) in ovarian cancer. Since EMT is a critical process involved in cancer metastasis and chemoresistance, targeting Pirh2 may be a promising strategy in chemoresistance therapy for ovarian cancer.

\section{$\mathrm{SIAH} 2$}

Seven in absentia homolog 2 (SIAH2) is an evolutionarily conserved RING-finger ubiquitin ligase. SIAH2 has been defined as a central regulator of tumorigenesis and tumor progression by mediating ubiquitination of diverse cellular substrates. SIAH2 has a catalytic RING domain on its $\mathrm{N}$-terminus followed by two zinc fingers and a C-terminal substrate-binding domain ${ }^{[116]}$. Increasing evidence reveals that SIAH2 proteins are also involved in multiple cellular processes, including transcription regulation, cell cycle, survival, hypoxic 
response, cellular clock function, cynaptic vesicle function in neurons, and mitochondrial biogenesis ${ }^{[117-119]}$. $\mathrm{SIAH} 2$ protein contributes to the progression of various malignant tumors, including breast carcinoma ${ }^{[120]}$, lung $^{[121]}$ and prostate tumors ${ }^{[122]}$, and oral cancer $^{[123]}$.

Some recent findings may explain the mechanisms through which SIAH2 mediates ovarian cancer chemoresistance. Qiu et al. ${ }^{[124]}$ demonstrated that SIAH2 expression was an independent factor for platinum chemotherapy resistance in patients with epithelial ovarian cancer, suggesting that SIAH2 protein plays an key role in chemotherapy resistance. Another study manifested that the levels of HIPK2 and DYRK2 were significantly elevated due to inhibition of SIAH2, leading to increased sensitivity of cells to DNA damage-induced apoptosis ${ }^{[125]}$. Shah et al ${ }^{[126]}$ indicated that SIAH2 inhibitor menadione could be used as an efficacious therapeutic strategy for melanoma via weakening hypoxia and MAPK signaling [Table 1]. Furthermore, SIAH2 can sufficiently improve responses to chemotherapy by attenuating HIF-1 $\alpha$-mediated angiogenesis and hypoxia signaling ${ }^{[127]}$. SIAH 2 may be reversely regulated by E2 and EGF, thereby causing drug resistance in cancer $^{[127]}$. These data indicate that SIAH2 may be a potential biomarker in evaluating tumor chemoresistance and poor clinical outcomes in patients with epithelial ovarian cancer.

\section{The RBR E3 ligases-RNF31 in ovarian cancer chemoresistance}

RING finger protein 31 (RNF31, also named HOIP) is the catalytic subunit of the E3 ubiquitin ligase LUBAC (linear ubiquitin assembly complex), which also consists of the components SHARPIN and HOIL-1L and regulates cisplatin-induced genotoxicity ${ }^{[128,129]}$. There is compelling evidence from largescale gene-drug association studies that RNF31 overexpression may contribute to cisplatin resistance in cancer ${ }^{[130]}$. Mackay identified RNF31 as a key regulator in response to cisplatin induced genotoxicity. Due to the potentiated apoptotic response, RNF31 deletion may enhance the cytogenetic toxicity of cisplatin in some cancer cell lines ${ }^{[131]}$. Cells deficient in RNF31 E3 ligase complex were cisplatin-sensitive due to a significant raise in caspase-3/8-mediated apoptosis and enhanced cisplatin-induced JNK activity. Moreover, evidence also suggests that cisplatin resistant ovarian cancer cells could recover sensitivity with shRNF31 knockdown ${ }^{[24]}$. These results imply that RNF31 is a potential target for developing platinum-based anticancer drugs in combinational chemotherapy.

\section{CONCLUSION AND PERSPECTIVE}

Research on E3 ubiquitin ligases has been gradually carried out in the field of chemotherapy resistance. As described above, some E3 ubiquitin ligases are promising targets for cancer therapies. Due to the specificity requirement of targeted therapy, inhibitors specifically targeting E3s may be highly specific drugs with few side effects. New methods with small molecule inhibitors against E3 ligase are considered to be suitable treatment strategies.

Proteolysis-targeting chimera (PROTAC), a useful technology for targeted protein degradation in cancer therapy, has been applied in the degradation of critical oncoproteins involved in malignant neoplastic disease, especially in hematological malignancies ${ }^{[132]}$. A PROTAC molecule is generally composed of a covalently linked ligand of an E3 ubiquitin ligase and a ligand (mostly small-molecule inhibitor) of the protein of interest. PROTAC binds to the protein of interest to recruit E3 ubiquitin ligase which in turn proximity-induce ubiquitination of the protein of interest and then degradation by endogenous $26 \mathrm{~S}$ proteasomes ${ }^{[132]}$. The BRD4 of bromodomain and extra-terminal domain (BET) proteins had been indicated to play a significant role in the progression of diverse cancers, such as ovarian cancer, acute myeloid leukemia, prostate cancer and Burkitt's lymphoma ${ }^{[133]}$. A recent study reveals that the anti-tumor activity of BET-PROTACs contributes to diminish cancer growth in an in vivo mouse xenograft model with cells resistant to bromodomain and extraterminal domain inhibitors, and are also very active in triple-negative breast cancer and ovarian cancer cell lines ${ }^{[134]}$. This suggests that PROTAC technology has a prominent potential in the perspective of ovarian cancer therapy. 
The ubiquitination activity of Cullin-RING E3 ligases requires the ubiquitin-like protein NEDD8, which covalently binds the E3 ligase cullin component, to perform normal functions. Compound MLN4924 is a small molecule inhibitor specifically targeting NEDD8 activation [Table 1]. MLN4924 has been shown to effectively block tumor cell proliferation in multiple preclinical models ${ }^{[135]}$. Phase I clinical trial of MLN4924 for non-hematologic malignancies has been completed, whereas other trials using MLN4924 in a range of solid tumors and hematologic malignancies are under way or planned (NCT00677170, NCT00911066). Bortezomib, the proteasome inhibitor, suggests the prospect of using specific E3 inhibitors in anticancer therapy. Studies demonstrated that inhibiting Hdm2 along with bortezomib sensitized cells to bortezomib and overturned bortezomib resistance ${ }^{[136]}$. Many compounds, including nutlin-3 (RO5045337), serdemetan, and NSC-207895, have all demonstrated in vitro anticancer activities ${ }^{[137-139]}$. Nutlin-3 may be used as a promising targeted therapy agent and has been registered for Phase I trials for an series of malignancies (NCT00559533, NCT00623870), although results from these studies have not yet been published. Recent studies have shown that nutlin-3 plays a key role in drug resistance by targeting the interaction between p53 and HDM2 [Table 1]. It induces apoptosis in chemoresistant ovarian cancer by reactivating p53 pathway as a small molecule regulator for $\mathrm{p} 53^{[96]}$. Furthermore, Shah et al ${ }^{[126]}$ also suggest that a small inhibitor of SIAH2, menadione, can be used as an effective therapeutic strategy for melanoma by weakening hypoxia and MAPK signaling [Table 1]. PARK2, a RING-between RING-type E3 ubiquitin ligase, has been implicated in various cellular activities including mitochondria homeostasis, stress response, protein turnover, xenophagy ${ }^{[140]}$, and metabolism. Frequent PARK2 inactivation has been recognized in diverse cancers. The copy number loss and loss of heterozygosity of Park 2 are found in ovarian cancer ${ }^{[141]}$, pancreatic adenocarcinoma ${ }^{[142]}$, and breast cancer ${ }^{[141]}$. Increasing evidence suggest that both Park2 and SPOP are associated with regulating PD-L1 stability, illustrating the need to excavate the roles of E3 ligases in animal models and clinic trial ${ }^{[143]}$. Given the recent success of immuno-oncology and CAR-T cell therapy, a further understanding of how E3 ligases affect macro-level phenotypes, such as tumor sensitivity to immunotherapies, may influence the design of clinical therapies.

The ubiquitination process is a dynamic process that is orchestrated by E3 ubiquitin ligases and DUBs. Increasing evidence support that DUBs are differentially expressed in numerous cancers such as pancreatic ductal adenocarcinoma, ovarian cancer, non-small cell lung cancer, and breast cancer ${ }^{[144,145]}$. Based on recent data, alterations of DUB activities are also involved in various pathological disorders consisting of malignant neoplastic diseases and multiple neurological disorders. Several DUBs have been identified as regulators in the development of ovarian cancer, including USP1, USP7, USP5, USP39, and UCHL1 ${ }^{[146]}$. One study shows that ubiquitin carboxyl terminal hydrolase 1 is a putative tumor suppressor in ovarian cancer cell lines and contributes to ovarian cancer cisplatin resistance ${ }^{[147]}$. Intriguingly, Sonego et al ${ }^{[148]}$ indicated that Snail was a USP1 target, opening the way to a novel strategy in overcoming platinum resistance and more successfully treating patients with ovarian cancer.These data suggest that DUBs may be explored as a promising therapeutic target for treatment of ovarian cancer and other diseases.

Increasing amount of evidence suggests that non-coding RNAs (ncRNAs) play important roles in most cancers cellular network and functions. Dysregulation of ncRNAs in cancer has also been reported to renovate drug responsiveness in chemoresistant cancer cells. Recent data showed that interaction between long non-coding RNA GHET1 (gastric carcinoma high expressed transcript 1) and the E3 ubiquitin ligase VHL (von Hippel-Lindau) blocked VHL-mediated degradation of HIF1 $\alpha$ (hypoxia-inducible factor-1 $\alpha$ ) and enhanced the protein level of HIF1 $\alpha$, which then promoted the proliferation of ovarian cancer cells $^{[149]}$. Hu et al. ${ }^{[150]}$ found that E3 ubiquitin-protein ligase MARCH7 (membrane-associated RING finger protein 7) interaction with MALAT1 modulates ATG7 by competing with miR-200a and promoting autophagy, metastasis and invasion in ovarian cancer. Another study found miR-96 boosting apoptosis through reduction of the antiapoptotic regulator XIAP and the p53 stability regulator UBE2N (ubiquitinconjugating enzyme E2N), regulating 5-FU sensitivity in colorectal cancer cells ${ }^{[151]}$. Furthermore, it is 
confirmed that miR-133b may reduce ovarian cancer chemotherapy resistance by silencing the expression of the drug-resistance-related proteins, glutathione S-transferase- $\pi$ and multidrug resistance protein $1^{[152]}$. In the future, the combination of ncRNAs with chemotherapy agents may show exciting efficacy in overturning chemotherapy resistance in ovarian cancer.

Broadly speaking, E3 ligases play important roles in mediating drug resistance. With the development and advancing of proteomics technology, more and more substrate proteins have been identified. Theoretically, the most efficacious treatment for the ubiquitin proteasome pathway is to block the E3 ligase at specific substrate recognition sites. However, due to the extreme complexity of the candidate small molecule drugs, blocking protein-protein interaction is very difficult. At present, many treatment strategies are still in largescale experimental studies. How to overcome clinical drug resistance through regulating the interaction between key signal transduction factors and E3 ligases is still the focus of current research and the most difficult issue. Further understanding of the mechanisms underlying E3-substrate interaction and function will provide a good theoretical base for clinically targeting E3 ligases for chemotherapy against drug resistant ovarian cancer in the future.

\section{DECLARATIONS}

\section{Authors' contributions}

Conceptualization: Meng Y, Han JH

Original draft writing and editing: Meng Y, Qiu L, Han JH

Figure Creating: Zhang S, Meng Y

\section{Availability of data and materials}

Not applicable.

\section{Financial support and sponsorship}

This work was supported by the National Natural Science Foundation of China (31972884, 81903083), the Foundation for Innovative Research Groups of the National Natural Science Foundation of China (81821002), National Clinical Research Center for Geriatrics (Z20201007), and 1.3.5 Project for Disciplines of Excellence, West China Hospital (ZYGD18003), Sichuan University.

\section{Conflicts of interest}

All authors declared that there are no conflicts of interest.

\section{Ethical approval and consent to participate}

Not applicable.

\section{Consent for publication}

Not applicable.

\section{Copyright}

(c) The Author(s) 2021.

\section{REFERENCES}

1. Popovic D, Vucic D, Dikic I. Ubiquitination in disease pathogenesis and treatment. Nat Med 2014;20:1242-53.

2. Mansour MA. Ubiquitination: Friend and foe in cancer. Int J Biochem Cell Biol 2018;101:80-93.

3. Wang D, Ma L, Wang B, Liu J, Wei W. E3 ubiquitin ligases in cancer and implications for therapies. Cancer Metastasis Rev 2017;36:683702.

4. Pickart CM, Eddins MJ. Ubiquitin: structures, functions, mechanisms. Biochim Biophys Acta 2004;1695:55-72.

5. Reyes-Turcu FE, Ventii KH, Wilkinson KD. Regulation and cellular roles of ubiquitin-specific deubiquitinating enzymes. Annu Rev Biochem 2009;78:363-97. 
6. Ramakrishna S, Suresh B, Baek KH. The role of deubiquitinating enzymes in apoptosis. Cell Mol Life Sci 2011;68:15-26.

7. Ramakrishna S, Suresh B, Baek KH. Biological functions of hyaluronan and cytokine-inducible deubiquitinating enzymes. Biochim Biophys Acta 2015;1855:83-91.

8. Richardson PG, Barlogie B, Berenson J, et al. A phase 2 study of bortezomib in relapsed, refractory myeloma. $N$ Engl J Med 2003;348:2609-17.

9. Hideshima T, Richardson P, Chauhan D, et al. The proteasome inhibitor PS-341 inhibits growth, induces apoptosis, and overcomes drug resistance in human multiple myeloma cells. Cancer Res 2001;61:3071-6.

10. Schmidt MHH, Dikic I. The Cbl interactome and its functions. Nat Rev Mol Cell Biol 2005;6:907-18.

11. Bray F, Ferlay J, Soerjomataram I, Siegel RL, Torre LA, Jemal A. Global cancer statistics 2018: GLOBOCAN estimates of incidence and mortality worldwide for 36 cancers in 185 countries. CA Cancer J Clin 2018;68:394-424.

12. Webb PM, Jordan SJ. Epidemiology of epithelial ovarian cancer. Best Pract Res Clin Obstet Gynaecol 2017;41:3-14.

13. Jazaeri AA, Shibata E, Park J, et al. Overcoming platinum resistance in preclinical models of ovarian cancer using the neddylation inhibitor MLN4924. Mol Cancer Ther 2013;12:1958-67.

14. Matulonis UA, Sood AK, Fallowfield L, Howitt BE, Sehouli J, Karlan BY. Ovarian cancer. Nat Rev Dis Primers 2016;2:16061.

15. Eltabbakh GH, Awtrey CS. Current treatment for ovarian cancer. Expert Opin Pharmacother 2001;2:109-24.

16. Amawi H, Sim HM, Tiwari AK, Ambudkar SV, Shukla S. ABC transporter-mediated multidrug-resistant cancer. Adv Exp Med Biol 2019;1141:549-80.

17. Li W, Zhang H, Assaraf YG, Zhao K, et al. Overcoming ABC transporter-mediated multidrug resistance: molecular mechanisms and novel therapeutic drug strategies. Drug Resist Updat 2016;27:14-29.

18. Perego P, Giarola M, Righetti SC, et al. Association between cisplatin resistance and mutation of $\mathrm{p} 53$ gene and reduced bax expression in ovarian carcinoma cell systems. Cancer Res 1996;56:556-62.

19. Reed JC, Miyashita T, Takayama S, et al. BCL-2 family proteins: regulators of cell death involved in the pathogenesis of cancer and resistance to therapy. $J$ Cell Biochem 1996;60:23-32.

20. Zheng N, Shabek N. Ubiquitin Ligases: Structure, function, and regulation. Anпи Rev Biochem 2017;86:129-57.

21. Fajner V, Maspero E, Polo S. Targeting HECT-type E3 ligases - insights from catalysis, regulation and inhibitors. FEBS Lett 2017;591:2636-47.

22. Berndsen CE, Wolberger C. New insights into ubiquitin E3 ligase mechanism. Nat Struct Mol Biol 2014;21:301-7.

23. Dove KK, Klevit RE. RING-Between-RING E3 Ligases: Emerging themes amid the variations. J Mol Biol 2017;429:3363-75.

24. Yang L, Chen J, Huang X, Zhang E, He J, Cai Z. Novel insights into E3 ubiquitin ligase in cancer chemoresistance. Am J Med Sci 2018;355:368-76.

25. Rotin D, Kumar S. Physiological functions of the HECT family of ubiquitin ligases. Nat Rev Mol Cell Biol 2009;10:398-409.

26. Ozkan E, Yu H, Deisenhofer J. Mechanistic insight into the allosteric activation of a ubiquitin-conjugating enzyme by RING-type ubiquitin ligases. Proc Natl Acad Sci U S A 2005;102:18890-5.

27. van der Reijden BA, Erpelinck-Verschueren CA, Lowenberg B, Jansen JH. TRIADs: a new class of proteins with a novel cysteine-rich signature. Protein Sci 1999;8:1557-61.

28. Morett E, Bork P. A novel transactivation domain in parkin. Trends Biochem Sci 1999;24:229-31.

29. Wenzel DM, Lissounov A, Brzovic PS, Klevit RE. UBCH7 reactivity profile reveals parkin and HHARI to be RING/HECT hybrids. Nature 2011;474:105-8.

30. Ho SR, Mahanic CS, Lee YJ, Lin WC. RNF144A, an E3 ubiquitin ligase for DNA-PKcs, promotes apoptosis during DNA damage. Proc Natl Acad Sci U S A 2014;111:E2646-55.

31. Kelsall IR, Duda DM, Olszewski JL, et al. TRIAD1 and HHARI bind to and are activated by distinct neddylated Cullin-RING ligase complexes. EMBO J 2013;32:2848-60.

32. Stieglitz B, Morris-Davies AC, Koliopoulos MG, Christodoulou E, Rittinger K. LUBAC synthesizes linear ubiquitin chains via a thioester intermediate. EMBO Rep 2012;13:840-6.

33. Smit JJ, Monteferrario D, Noordermeer SM, van Dijk WJ, van der Reijden BA, Sixma TK. The E3 ligase HOIP specifies linear ubiquitin chain assembly through its RING-IBR-RING domain and the unique LDD extension. EMBO J 2012;31:3833-44.

34. Li W, Bengtson MH, Ulbrich A, et al. Genome-wide and functional annotation of human E3 ubiquitin ligases identifies MULAN, a mitochondrial E3 that regulates the organelle's dynamics and signaling. PLoS One 2008;3:e1487.

35. Scheffner M, Staub O. HECT E3s and human disease. BMC Biochem 2007;8 Suppl 1:S6.

36. Ingham RJ, Gish G, Pawson T. The Nedd4 family of E3 ubiquitin ligases: functional diversity within a common modular architecture. Oncogene 2004;23:1972-84.

37. Scheffner M, Kumar S. Mammalian HECT ubiquitin-protein ligases: biological and pathophysiological aspects. Biochim Biophys Acta 2014;1843:61-74.

38. Zhu K, Shan Z, Chen X, et al. Allosteric auto-inhibition and activation of the Nedd4 family E3 ligase Itch. EMBO Rep 2017;18:1618-30.

39. Yao W, Shan Z, Gu A, Fu M, Shi Z, Wen W. WW domain-mediated regulation and activation of E3 ubiquitin ligase Suppressor of Deltex. J Biol Chem 2018;293:16697-708.

40. Yang Q, Zhao J, Cui M, Gi S, Wang W, Han X. Nedd4L expression is decreased in ovarian epithelial cancer tissues compared to ovarian non-cancer tissue. J Obstet Gynaecol Res 2015;41:1959-64.

41. Sun H, Ma H, Wang J, et al. Phosphatase and tensin homolog deleted on chromosome 10 degradation induced by NEDD4 promotes acquired erlotinib resistance in non-small-cell lung cancer. Tumour Biol 2017;39:1010428317709639. 
42. Huang X, Gu H, Zhang E, et al. The NEDD4-1 E3 ubiquitin ligase: A potential molecular target for bortezomib sensitivity in multiple myeloma. Int J Cancer 2020;146:1963-78.

43. Akkaya BG, Zolnerciks JK, Ritchie TK, et al. The multidrug resistance pump ABCB1 is a substrate for the ubiquitin ligase NEDD4-1. Mol Membr Biol 2015;32:39-45.

44. Yin Q, Wyatt CJ, Han T, Smalley KSM, Wan L. ITCH as a potential therapeutic target in human cancers. Semin Cancer Biol 2020;67:11730.

45. Riling C, Kamadurai H, Kumar S, et al. Itch WW Domains Inhibit Its E3 Ubiquitin Ligase Activity by Blocking E2-E3 Ligase Transthiolation. J Biol Chem 2015;290:23875-87.

46. Abedini MR, Muller EJ, Brun J, Bergeron R, Gray DA, Tsang BK. Cisplatin induces p53-dependent FLICE-like inhibitory protein ubiquitination in ovarian cancer cells. Cancer Res 2008;68:4511-7.

47. Abedini MR, Muller EJ, Bergeron R, Gray DA, Tsang BK. Akt promotes chemoresistance in human ovarian cancer cells by modulating cisplatin-induced, p53-dependent ubiquitination of FLICE-like inhibitory protein. Oncogene 2010;29:11-25.

48. Abedini MR, Wang PW, Huang YF, et al. Cell fate regulation by gelsolin in human gynecologic cancers. Proc Natl Acad Sci U S A 2014;111:14442-7.

49. Henderson MJ, Russell AJ, Hird S, et al. EDD, the human hyperplastic discs protein, has a role in progesterone receptor coactivation and potential involvement in DNA damage response. J Biol Chem 2002;277:26468-78.

50. Munoz MA, Saunders DN, Henderson MJ, et al. The E3 ubiquitin ligase EDD regulates S-phase and G(2)/M DNA damage checkpoints. Cell Cycle 2007;6:3070-7.

51. Gudjonsson T, Altmeyer M, Savic V, et al. TRIP12 and UBR5 suppress spreading of chromatin ubiquitylation at damaged chromosomes. Cell 2012;150:697-709.

52. Wang Y, Argiles-Castillo D, Kane EI, Zhou A, Spratt DE. HECT E3 ubiquitin ligases - emerging insights into their biological roles and disease relevance. J Cell Sci 2020;133:jcs228072.

53. Clancy JL, Henderson MJ, Russell AJ, et al. EDD, the human orthologue of the hyperplastic discs tumour suppressor gene, is amplified and overexpressed in cancer. Oncogene 2003;22:5070-81.

54. O'Brien PM, Davies MJ, Scurry JP, et al. The E3 ubiquitin ligase EDD is an adverse prognostic factor for serous epithelial ovarian cancer and modulates cisplatin resistance in vitro. Br J Cancer 2008;98:1085-93.

55. Bradley A, Zheng H, Ziebarth A, et al. EDD enhances cell survival and cisplatin resistance and is a therapeutic target for epithelial ovarian cancer. Carcinogenesis 2014;35:1100-9.

56. Eblen ST, Bradley A. MOAP-1, UBR5 and cisplatin resistance in ovarian cancer. Transl Cancer Res 2017;6:S18-21.

57. Matsuura K, Huang NJ, Cocce K, Zhang L, Kornbluth S. Downregulation of the proapoptotic protein MOAP-1 by the UBR5 ubiquitin ligase and its role in ovarian cancer resistance to cisplatin. Oncogene 2017;36:1698-706.

58. Burger AM, Seth AK. The ubiquitin-mediated protein degradation pathway in cancer: therapeutic implications. Eur $J$ Cancer 2004;40:2217-29.

59. Morreale FE, Walden H. Types of Ubiquitin Ligases. Cell 2016;165:248.e1.

60. Cui D, Xiong X, Zhao Y. Cullin-RING ligases in regulation of autophagy. Cell Div 2016;11:8.

61. Bulatov E, Ciulli A. Targeting Cullin-RING E3 ubiquitin ligases for drug discovery: structure, assembly and small-molecule modulation. Biochem J 2015;467:365-86.

62. Pan WW, Zhou JJ, Yu C, et al. Ubiquitin E3 ligase CRL4(CDT2/DCAF2) as a potential chemotherapeutic target for ovarian surface epithelial cancer. J Biol Chem 2013;288:29680-91.

63. Lydeard JR, Schulman BA, Harper JW. Building and remodelling Cullin-RING E3 ubiquitin ligases. EMBO Rep 2013;14:1050-61.

64. Chen Z, Sui J, Zhang F, Zhang C. Cullin family proteins and tumorigenesis: genetic association and molecular mechanisms. $J$ Cancer 2015;6:233-42.

65. Zhao Y, Sun Y. Cullin-RING Ligases as attractive anti-cancer targets. Curr Pharm Des 2013;19:3215-25.

66. Skaar JR, Pagan JK, Pagano M. SCF ubiquitin ligase-targeted therapies. Nat Rev Drug Discov 2014;13:889-903.

67. Lee EK, Diehl JA. SCFs in the new millennium. Oncogene 2014;33:2011-8.

68. Zhang Q, Wang W, Gao Q. beta-TRCP-mediated AEBP2 ubiquitination and destruction controls cisplatin resistance in ovarian cancer. Biochem Biophys Res Commun 2020;523:274-9.

69. Gutgemann I, Lehman NL, Jackson PK, Longacre TA. Emil protein accumulation implicates misregulation of the anaphase promoting complex/cyclosome pathway in ovarian clear cell carcinoma. Mod Pathol 2008;21:445-54.

70. Chou JL, Su HY, Chen LY, et al. Promoter hypermethylation of FBXO32, a novel TGF-beta/SMAD4 target gene and tumor suppressor, is associated with poor prognosis in human ovarian cancer. Lab Invest 2010;90:414-25.

71. Kim S, Kon M, DeLisi C. Pathway-based classification of cancer subtypes. Biol Direct 2012;7:21.

72. Chiu HW, Chang JS, Lin HY, et al. FBXL7 Upregulation Predicts a Poor Prognosis and Associates with a Possible Mechanism for Paclitaxel Resistance in Ovarian Cancer. J Clin Med 2018;7:330.

73. Kamran M, Long ZJ, Xu D,et al. Aurora kinase A regulates Survivin stability through targeting FBXL7 in gastric cancer drug resistance and prognosis. Oncogenesis 2017;6:e298.

74. He J, Kallin EM, Tsukada Y, Zhang Y. The H3K36 demethylase Jhdm1b/Kdm2b regulates cell proliferation and senescence through p15(Ink4b). Nat Struct Mol Biol 2008;15:1169-75.

75. Sanchez C, Sanchez I, Demmers JA, Rodriguez P, Strouboulis J, Vidal M. Proteomics analysis of Ring1B/Rnf2 interactors identifies a novel complex with the Fbxl10/Jhdm1B histone demethylase and the Bcl6 interacting corepressor. Mol Cell Proteomics 2007;6:820-34. 
76. Yan M, Yang X, Shen R, et al. miR-146b promotes cell proliferation and increases chemosensitivity, but attenuates cell migration and invasion via FBXL10 in ovarian cancer. Cell Death Dis 2018;9:1123.

77. Wang X, Arceci A, Bird K, et al. VprBP/DCAF1 regulates the degradation and nonproteolytic activation of the cell cycle transcription factor FoxM1. Mol Cell Biol 2017;37:e00609-16.

78. Hu X, Meng Y, Xu L, et al. Cul4 E3 ubiquitin ligase regulates ovarian cancer drug resistance by targeting the antiapoptotic protein BIRC3. Cell Death Dis 2019;10:104.

79. Jang SM, Nathans JF, Fu H, et al. The RepID-CRL4 ubiquitin ligase complex regulates metaphase to anaphase transition via BUB3 degradation. Nat Commun 2020;11:24.

80. Acquaviva C, Pines J. The anaphase-promoting complex/cyclosome: APC/C. J Cell Sci 2006;119:2401-4.

81. Peters JM. The anaphase promoting complex/cyclosome: a machine designed to destroy. Nat Rev Mol Cell Biol 2006; 7:644-56.

82. Raab M, Kobayashi NF, Becker S, et al. Boosting the apoptotic response of high-grade serous ovarian cancers with CCNE1 amplification to paclitaxel in vitro by targeting APC/C and the pro-survival protein MCL-1. Int J Cancer 2020;146:1086-98.

83. Belur Nagaraj A, Kovalenko O, Avelar R, et al. Mitotic exit dysfunction through the deregulation of APC/C characterizes cisplatinresistant state in epithelial ovarian cancer. Clin Cancer Res 2018;24:4588-601.

84. Deveraux QL, Takahashi R, Salvesen GS, Reed JC. X-linked IAP is a direct inhibitor of cell-death proteases. Nature 1997;388:300-4.

85. Yang YL, Li XM. The IAP family: endogenous caspase inhibitors with multiple biological activities. Cell Res 2000;10:169-77.

86. Li J, Feng Q, Kim JM, et al. Human ovarian cancer and cisplatin resistance: possible role of inhibitor of apoptosis proteins. Endocrinology 2001;142:370-80.

87. Sasaki H, Sheng Y, Kotsuji F, Tsang BK. Down-regulation of X-linked inhibitor of apoptosis protein induces apoptosis in chemoresistant human ovarian cancer cells. Cancer Res 2000;60:5659-66.

88. Fraser M, Leung B, Jahani-Asl A, Yan X, Thompson WE, Tsang BK. Chemoresistance in human ovarian cancer: the role of apoptotic regulators. Reprod Biol Endocrinol 2003;1:66.

89. He X, Khurana A, Maguire JL, Chien J, Shridhar V. HtrA1 sensitizes ovarian cancer cells to cisplatin-induced cytotoxicity by targeting XIAP for degradation. Int $J$ Cancer 2012;130:1029-35.

90. Yang X, Xing H, Gao Q, et al. Regulation of HtrA2/Omi by X-linked inhibitor of apoptosis protein in chemoresistance in human ovarian cancer cells. Gynecol Oncol 2005;97:413-21.

91. Shangary S, Wang S. Targeting the MDM2-p53 interaction for cancer therapy. Clin Cancer Res 2008;14:5318-24.

92. Iwakuma T, Lozano G. MDM2, an introduction. Mol Cancer Res 2003;1:993-1000.

93. Kubbutat MH, Jones SN, Vousden KH. Regulation of p53 stability by Mdm2. Nature 1997;387:299-303.

94. Honda R, Tanaka H, Yasuda H. Oncoprotein MDM2 is a ubiquitin ligase E3 for tumor suppressor p53. FEBS Lett 1997;420:25-7.

95. Haupt Y, Maya R, Kazaz A, Oren M. Mdm2 promotes the rapid degradation of p53. Nature 1997;387:296-9.

96. Oliner JD, Kinzler KW, Meltzer PS, George DL, Vogelstein B. Amplification of a gene encoding a p53-associated protein in human sarcomas. Nature 1992;358:80-3.

97. Mir R, Tortosa A, Martinez-Soler F, et al. Mdm2 antagonists induce apoptosis and synergize with cisplatin overcoming chemoresistance in TP53 wild-type ovarian cancer cells. Int J Cancer 2013;132:1525-36.

98. Wu AY, Gu LY, Cang W, et al. Fn14 overcomes cisplatin resistance of high-grade serous ovarian cancer by promoting Mdm2-mediated p53-R248Q ubiquitination and degradation. J Exp Clin Cancer Res 2019;38:176.

99. Cui L, Zhou F, Chen C, Wang CC. Overexpression of CCDC69 activates p14(ARF)/MDM2/p53 pathway and confers cisplatin sensitivity. J Ovarian Res 2019;12:4.

100. Braschi E, Zunino R, McBride HM. MAPL is a new mitochondrial SUMO E3 ligase that regulates mitochondrial fission. EMBO Rep 2009;10:748-54.

101. Prudent J, Zunino R, Sugiura A, Mattie S, Shore GC, McBride HM. MAPL SUMOylation of Drp1 Stabilizes an ER/Mitochondrial Platform Required for Cell Death. Mol Cell 2015;59:941-55.

102. Zhang B, Huang J, Li HL, et al. GIDE is a mitochondrial E3 ubiquitin ligase that induces apoptosis and slows growth. Cell Res 2008;18:900-10.

103. Jung JH, Bae S, Lee JY, et al. E3 ubiquitin ligase Hades negatively regulates the exonuclear function of p53. Cell Death Differ 2011;18:1865-75.

104. Min B, Ryu J, Chi SW, Yi GS. Ubiquitination-dependent degradation of p73 by the mitochondrial E3 ubiquitin ligase Hades. Biochem Biophys Res Commun 2015;467:316-21.

105. Yun J, Puri R, Yang H, et al. MUL1 acts in parallel to the PINK1/parkin pathway in regulating mitofusin and compensates for loss of PINK1/parkin. Elife 2014;3:e01958.

106. Kim SY, Kim HJ, Byeon HK, Kim DH, Kim CH. FOXO3 induces ubiquitylation of AKT through MUL1 regulation. Oncotarget 2017;8:110474-89.

107. Li J, Qi W, Chen G, et al. Mitochondrial outer-membrane E3 ligase MUL1 ubiquitinates ULK1 and regulates selenite-induced mitophagy. Autophagy 2015;11:1216-29.

108. Peng J, Ren KD, Yang J, Luo XJ. Mitochondrial E3 ubiquitin ligase 1: A key enzyme in regulation of mitochondrial dynamics and functions. Mitochondrion 2016;28:49-53.

109. Jenkins K, Khoo JJ, Sadler A, et al. Mitochondrially localised MUL1 is a novel modulator of antiviral signaling. Immunol Cell Biol 2013;91:321-30.

110. Doiron K, Goyon V, Coyaud E, Rajapakse S, Raught B, McBride HM. The dynamic interacting landscape of MAPL reveals essential functions for SUMOylation in innate immunity. Sci Rep 2017;7:107. 
111. Lee J, An S, Jung JH, et al. MUL1 E3 ligase regulates the antitumor effects of metformin in chemoresistant ovarian cancer cells via AKT degradation. Int J Oncol 2019;54:1833-42.

112. Beitel LK, Elhaji YA, Lumbroso R, et al. Cloning and characterization of an androgen receptor N-terminal-interacting protein with ubiquitin-protein ligase activity. J Mol Endocrinol 2002;29:41-60.

113. Daks AA, Melino D, Barlev NA. [The role of different E3 ubiquitin ligases in regulation of the P53 tumor suppressor protein]. Tsitologiia 2013;55:673-87.

114. Wang Z, Yang B, Dong L, Peng B, He X, Liu W. A novel oncoprotein Pirh2: rising from the shadow of MDM2. Cancer Sci 2011;102:90917.

115. Yang-Hartwich Y, Tedja R, Roberts CM, et al. p53-Pirh2 Complex Promotes Twist1 Degradation and Inhibits EMT. Mol Cancer Res 2019;17:153-64.

116. Reed JC, Ely KR. Degrading liaisons: Siah structure revealed. Nat Struct Biol 2002;9:8-10.

117. Christian PA, Fiandalo MV, Schwarze SR. Possible role of death receptor-mediated apoptosis by the E3 ubiquitin ligases Siah2 and POSH. Mol Cancer 2011;10:57.

118. Kilroy G, Carter LE, Newman S, et al. The ubiquitin ligase Siah2 regulates obesity-induced adipose tissue inflammation. Obesity (Silver Spring) 2015;23:2223-32.

119. Sun RC, Denko NC. Hypoxic regulation of glutamine metabolism through HIF1 and SIAH2 supports lipid synthesis that is necessary for tumor growth. Cell Metab 2014;19:285-92.

120. Zhang B, Li Y, Zheng X, et al. A common variant in the SIAH2 locus is associated with estrogen receptor-positive breast cancer in the Chinese Han population. PLoS One 2013;8:e79365.

121. Muller S, Chen Y, Ginter T, et al. SIAH2 antagonizes TYK2-STAT3 signaling in lung carcinoma cells. Oncotarget 2014;5:3184-96.

122. Rizzardi AE, Rosener NK, Koopmeiners JS, et al. Evaluation of protein biomarkers of prostate cancer aggressiveness. BMC Cancer 2014;14:244.

123. Hsieh SC, Kuo SN, Zheng YH, Tsai MH, Lin YS, Lin JH. The E3 ubiquitin ligase SIAH2 is a prosurvival factor overexpressed in oral cancer. Anticancer Res 2013;33:4965-73.

124. Qiu J, Geng Y-C, Meng F. SIAH 2 expression predicts chemoresistance and poor clinical outcomes in patients with epithelial ovarian cancer. Int J Clin Exp Pathol 2016;9:8432-9.

125. Perez M, Garcia-Limones C, Zapico I, et al. Mutual regulation between SIAH2 and DYRK2 controls hypoxic and genotoxic signaling pathways. J Mol Cell Biol 2012;4:316-30.

126. Shah M, Stebbins JL, Dewing A, Qi J, Pellecchia M, Ronai ZA. Inhibition of Siah2 ubiquitin ligase by vitamin K3 (menadione) attenuates hypoxia and MAPK signaling and blocks melanoma tumorigenesis. Pigment Cell Melanoma Res 2009;22:799-808.

127. Jansen MP, Ruigrok-Ritstier K, Dorssers LC, et al. Downregulation of SIAH2, an ubiquitin E3 ligase, is associated with resistance to endocrine therapy in breast cancer. Breast Cancer Res Treat 2009;116:263-71.

128. Emmerich $\mathrm{CH}$, Ordureau A, Strickson S, et al. Activation of the canonical IKK complex by K63/M1-linked hybrid ubiquitin chains. Proc Natl Acad Sci U S A 2013;110:15247-52.

129. Kirisako T, Kamei K, Murata S, et al. A ubiquitin ligase complex assembles linear polyubiquitin chains. EMBO J 2006;25:4877-87.

130. Garnett MJ, Edelman EJ, Heidorn SJ, et al. Systematic identification of genomic markers of drug sensitivity in cancer cells. Nature 2012;483:570-5.

131. MacKay C, Carroll E, Ibrahim AFM, et al. E3 ubiquitin ligase HOIP attenuates apoptotic cell death induced by cisplatin. Cancer Res 2014;74:2246-57.

132. Li X, Song Y. Proteolysis-targeting chimera (PROTAC) for targeted protein degradation and cancer therapy. J Hematol Oncol 2020;13:50.

133. Salami J, Crews CM. Waste disposal-An attractive strategy for cancer therapy. Science 2017;355:1163-7.

134. Noblejas-Lopez MDM, Nieto-Jimenez C, Burgos M, et al. Activity of BET-proteolysis targeting chimeric (PROTAC) compounds in triple negative breast cancer. $J$ Exp Clin Cancer Res 2019;38:383.

135. Soucy TA, Smith PG, Milhollen MA, et al. An inhibitor of NEDD8-activating enzyme as a new approach to treat cancer. Nature 2009;458:732-6.

136. Ooi MG, Hayden PJ, Kotoula V, et al. Interactions of the $\mathrm{Hdm} 2 / \mathrm{p} 53$ and proteasome pathways may enhance the antitumor activity of bortezomib. Clin Cancer Res 2009;15:7153-60.

137. Vassilev LT, Vu BT, Graves B, et al. In vivo activation of the p53 pathway by small-molecule antagonists of MDM2. Science 2004;303:844-8.

138. Chargari C, Leteur C, Angevin E, et al. Preclinical assessment of JNJ-26854165 (Serdemetan), a novel tryptamine compound with radiosensitizing activity in vitro and in tumor xenografts. Cancer Lett 2011;312:209-18.

139. Wang H, Ma X, Ren S, Buolamwini JK, Yan C. A small-molecule inhibitor of MDMX activates p53 and induces apoptosis. Mol Cancer Ther 2011;10:69-79.

140. Manzanillo PS, Ayres JS, Watson RO, et al. The ubiquitin ligase parkin mediates resistance to intracellular pathogens. Nature 2013;501:512-6.

141. Cesari R, Martin ES, Calin GA, et al. Parkin, a gene implicated in autosomal recessive juvenile parkinsonism, is a candidate tumor suppressor gene on chromosome 6q25-q27. Proc Natl Acad Sci U S A 2003;100:5956-61.

142. Sun X, Liu M, Hao J, et al. Parkin deficiency contributes to pancreatic tumorigenesis by inducing spindle multipolarity and misorientation. Cell Cycle 2013;12:1133-41.

143. Ong JY, Torres JZ. E3 ubiquitin ligases in cancer and their pharmacological targeting. In: Summers M, editor. Ubiquitin Proteasome System-Current Insights into Mechanism Cellular Regulation and Disease. IntechOpen;2019. 
144. Zhang L, Xu B, Qiang Y, et al. Overexpression of deubiquitinating enzyme USP28 promoted non-small cell lung cancer growth. $J$ Cell Mol Med 2015;19:799-805.

145. Cox JL, Wilder PJ, Wuebben EL, Ouellette MM, Hollingsworth MA, Rizzino A. Context-dependent function of the deubiquitinating enzyme USP9X in pancreatic ductal adenocarcinoma. Cancer Biol Ther 2014;15:1042-52.

146. Tanguturi P, Kim KS, Ramakrishna S. The role of deubiquitinating enzymes in cancer drug resistance. Cancer Chemother Pharmacol 2020;85:627-39.

147. Jin C, Yu W, Lou X, et al. UCHL1 Is a putative tumor suppressor in ovarian cancer cells and contributes to cisplatin resistance. $J$ Cancer 2013;4:662-70.

148. Sonego M, Pellarin I, Costa A, et al. USP1 links platinum resistance to cancer cell dissemination by regulating Snail stability. Sci Adv 2019;5:eaav3235.

149. Liu D, Li H. Long non-coding RNA GEHT1 promoted the proliferation of ovarian cancer cells via modulating the protein stability of HIF1alpha. Biosci Rep 2019;39:BSR20181650.

150. Hu J, Zhang L, Mei Z, et al. Interaction of E3 Ubiquitin Ligase MARCH7 with Long Noncoding RNA MALAT1 and Autophagy-Related Protein ATG7 Promotes Autophagy and Invasion in Ovarian Cancer. Cell Physiol Biochem 2018;47:654-66.

151. Kim SA, Kim I, Yoon SK, Lee EK, Kuh HJ. Indirect modulation of sensitivity to 5-fluorouracil by microRNA-96 in human colorectal cancer cells. Arch Pharm Res 2015;38:239-48.

152. Chen S, Jiao JW, Sun KX, Zong ZH, Zhao Y. MicroRNA-133b targets glutathione S-transferase pi expression to increase ovarian cancer cell sensitivity to chemotherapy drugs. Drug Des Devel Ther 2015;9:5225-35.

153. Chang L, Kamata H, Solinas G, Luo JL, Maeda S, Venuprasad K, Liu YC, Karin M. The E3 ubiquitin ligase itch couples JNK activation to TNFalpha-induced cell death by inducing c-FLIP(L) turnover. Cell 2006;124:601-13. 